\title{
Carboidratos foliares durante a floração e os estádios iniciais de crescimento de frutilhos em tangerineira 'Ponkan'
}

\author{
Rodrigo Amato Moreira ${ }^{(1)}$, Maria do Céu Monteiro da $\mathrm{Cruz}^{(2)}$, Miriã Cristina Pereira Fagundes ${ }^{(2)}$, \\ Lílian de Araújo Pantoja ${ }^{(2)}$ e Alexandre Soares dos Santos ${ }^{(2)}$
}

\begin{abstract}
(1)Universidade Federal de Lavras, Caixa Postal 3037, CEP 37200-000 Lavras, MG, Brasil. E-mail: amatomoreira@yahoo.com.br (2)Universidade Federal dos Vales Jequitinhonha e Mucuri, Departamento de Agronomia, Campus JK, Rodovia MGT 367, Km 583, no 5.000, Alto da Jacuba, CEP 39100-000 Diamantina, MG, Brasil. E-mail: m_mariceu@yahoo.com.br, miria.agro@yahoo.com.br, I.pantoja@ufvjm.edu.br, alexandre.soares@ufvjm.edu.br
\end{abstract}

Resumo - O objetivo deste trabalho foi avaliar os teores de carboidratos foliares em tangerineira 'Ponkan' (Citrus reticulata), durante o pleno florescimento e os estádios iniciais de crescimento dos frutilhos, e identificar a melhor época para realização do raleio químico. O experimento foi realizado durante dois anos de produção (2009/2010 e 2010/2011), com quatro épocas de amostragem de folhas: 0, 30, 60 e 90 dias após o pleno florescimento. Utilizou-se o delineamento de blocos ao acaso, com parcelas subdivididas no tempo, quatro repetições e quatro plantas por parcela. Para determinar a utilização dos carboidratos pelas plantas, foram avaliados os teores de açúcares solúveis, açúcares redutores e amido na matéria seca das folhas. Nas mesmas épocas de amostragem foliar, o tamanho dos frutilhos também foi determinado. Os teores foliares de carboidratos solúveis aumentam e os de amido diminuem entre 35 e 50 dias após o pleno florescimento. No final da fase de fixação dos frutilhos, a partir dos 50 dias após o pleno florescimento, os teores de açúcares solúveis nas folhas diminuem. A melhor época para a realização do raleio químico em tangerineira 'Ponkan' é logo após a fase de queda fisiológica, quando os frutilhos atingirem cerca de $18 \mathrm{~mm}$ de diâmetro, aos 50 dias após o pleno florescimento.

Termos para indexação: Citrus reticulata, alternância de produção, pegamento de frutilhos, qualidade de frutos, raleio químico, reservas nutricionais.

\section{Leaf carbohydrates during flowering and early growth stages of fruitlets in 'Ponkan' mandarin tree}

\begin{abstract}
The objective of this work was to evaluate the levels of carbohydrates in the leaves of 'Ponkan' mandarin tree (Citrus reticulata), during full flowering and early growth stages of fruitlets, and to identify the best time to perform chemical thinning. The experiment was carried out for two production years (2009/2010 and 2010/2011), with four sampling times of leaves: 0,30, 60, and 90 days after full flowering. A randomized complete block design, split-plotted in time with four replicates and four plants per plot, was used. To determine the use of carbohydrates by plants, the contents of soluble sugars, reducing sugars, and starch in the dry matter of leaves were evaluated. At the same leaf sampling times, fruitlet size was also determined. Leaf contents of soluble carbohydrates increase and the ones of starch decrease between 35 and 50 days after full flowering. At the end of the fruit setting phase, from the $50^{\text {th }}$ day after full flowering, the contents of soluble sugars in leaves reduce. The best time to perform chemical thinning in 'Ponkan' mandarin tree is soon after the physiological drop phase, when the fruitlets reach around $18 \mathrm{~mm}$, at the $50^{\text {th }}$ day after full flowering.
\end{abstract}

Index terms: Citrus reticulata, alternate bearing, fruitlet onset, fruit quality, chemical thinning, nutritional reserves.

\section{Introdução}

A tangerineira 'Ponkan' (Citrus reticulata Blanco) está sujeita à alternância de produção, caracterizada por anos de produção excessiva de frutas intercalados com anos de baixa produção (Maia et al., 2010; Moreira et al., 2011b; Cruz \& Moreira, 2012). Nos anos de alta produção, as frutas têm seu tamanho reduzido pela grande competição por fotoassimilados (Duarte et al., 2011). No ano subsequente, em razão do esgotamento das reservas nutricionais das plantas, ocorre baixa ou até mesmo ausência de produção (Cruz et al., 2011), o que prejudica a rentabilidade da atividade (Moreira et al., 2011a).

Os carboidratos acumulados no sistema radicular e nas folhas das plantas consistem em importante fonte 
de reservas para a formação e o desenvolvimento de flores e frutos (Bolding et al., 2003; Cruz et al., 2007), uma vez que a produção diária de carboidratos pelas plantas não atende à demanda total nessas fases (Bustan \& Goldschmidt, 1998). Portanto, práticas de manejo que proporcionem a manutenção das reservas de carboidratos nas tangerineiras 'Ponkan' são importantes para promover floração no ano seguinte e para o desenvolvimento de frutos com qualidade adequada. Entre essas práticas, destaca-se o raleio químico (Ramos et al., 2009; Cruz et al., 2009, 2010, 2011; Moreira, et al., 2011a, 2011b).

O período de realização do raleio químico varia de acordo com as condições climáticas de cada região, que influenciam a época de floração e o desenvolvimento dos frutos. Ramos et al. (2009) verificaram eficiência do raleio químico em 'Ponkan', quando os frutilhos estavam no estágio entre 15 e $20 \mathrm{~mm}$ de diâmetro. No entanto, a utilização do raleio químico em estágios mais avançados, com frutilhos de 25 a $40 \mathrm{~mm}$ de diâmetro, também proporciona resultados satisfatórios para essa cultivar (Cruz et al., 2010, 2011; Moreira et al., 2011a, 2011b, 2012, 2013a, 2013b; Cruz \& Moreira, 2012).

Dessa forma, a determinação dos níveis de carboidratos foliares durante a floração e o desenvolvimento inicial dos frutos é relevante para determinar, com precisão, qual a época mais adequada para o raleio, cuja eficiência pode diminuir quando feito com frutilhos com diâmetro maior, pelo desperdício de fotoassimilados (Ruiz et al., 2001), e também quando realizado na florada, pois a eliminação de flores pode favorecer o pegamento de frutilhos (Zaragoza et al., 1992).

O objetivo deste trabalho foi avaliar os teores de carboidratos foliares em tangerineira 'Ponkan', durante o pleno florescimento e os estádios iniciais de crescimento dos frutilhos, e identificar a melhor época para realização do raleio químico.

\section{Material e Métodos}

O experimento foi realizado em pomar comercial, não irrigado, de tangerineira 'Ponkan' (C. reticulata), no Município de Perdões, na região sul de Minas Gerais $\left(21^{\circ} 05^{\prime} 27^{\prime \prime} \mathrm{S}, 45^{\circ} 05^{\prime} 27^{\prime \prime} \mathrm{W}\right.$, altitude $\left.814 \mathrm{~m}\right)$.

Foram utilizadas tangerineiras de 13 anos de idade, enxertadas sobre o limoeiro 'Cravo'
(C. limonia Osbeck), cultivadas no espaçamento de 6x3 m, em Argissolo Amarelo distrófico típico, com $59 \%$ de argila, $28 \%$ de silte e $13 \%$ de areia.

A adubação anual de produção do pomar foi realizada com aplicação de $300 \mathrm{~g}$ de superfosfato simples e $20 \mathrm{~L}$ de esterco de curral curtido por planta, em agosto, depois da colheita. O cobre foi aplicado com adubação foliar, tendo-se usado $600 \mathrm{~L} \mathrm{ha}^{-1}$ de calda a $2,5 \%$ de oxicloreto de cobre. Além disso, foram aplicados, em cada ano, $2 \mathrm{~kg}$ por planta do formulado $\mathrm{N}-\mathrm{P}_{2} \mathrm{O}_{5}-\mathrm{K}_{2} \mathrm{O}$ (20-05-20), divididos em quatro aplicações, com intervalo de 40 dias, com início na floração (outubro/novembro). Também foram realizadas quatro pulverizações foliares com $1,5 \mathrm{~L}$ por hectare do fertilizante foliar Citrolino $(10,0 \%$ de $\mathrm{N}$; $3,0 \%$ de $\mathrm{S} ; 1,0 \%$ de $\mathrm{Mg} ; 3,0 \%$ de $\mathrm{Zn} ; 2,0 \%$ de $\mathrm{Mn}$; $0,1 \%$ de Mo; $8,0 \%$ de Ca e $0,5 \%$ de B), em $600 \mathrm{~L} \mathrm{ha}^{-1}$ de calda, a cada 40 dias, a partir de novembro.

Os dados meteorológicos mensais de precipitação, temperaturas máximas, mínimas e médias foram obtidos na Estação Meteorológica de Lavras, MG (Figura 1).

Para a determinação dos teores de carboidratos, foram retiradas amostras de folhas de ramos produtivos, em parcelas divididas no tempo, com quatro épocas de amostragem: 0, 30, 60 e 90 dias após o pleno florescimento, em dois anos de produção (2009/2010 e 2010/2011). Utilizou-se o delineamento em blocos ao acaso, com quatro repetições e quatro plantas por parcela.

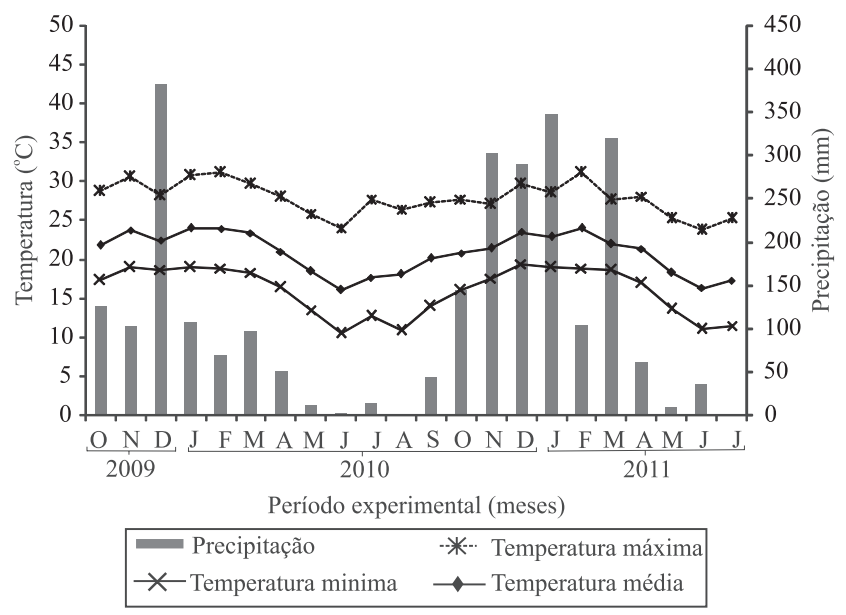

Figura 1. Valores médios mensais de precipitação e de temperaturas máxima, média e mínima, durante o período experimental. Dados obtidos da Estação Meteorológica de Lavras, MG. 
Foram coletadas, no período da manhã, a terceira e a quarta folha madura a partir do frutilho, num total de 48 folhas por parcela. Em cada época de amostragem, foi determinado o diâmetro transversal de 100 frutilhos por parcela.

As folhas foram lavadas em água destilada, imediatamente após a amostragem, e colocadas em estufa de circulação forçada de ar, a $65^{\circ} \mathrm{C}$, por 72 horas, quando atingiram massa constante. As amostras foram moídas e levadas ao Laboratório de Bioprocessos e Biotransformação, da Universidade Federal dos Vales do Jequitinhonha e Mucuri, Campus de Diamantina, para análise dos teores de carboidratos na matéria seca.

Os extratos para a determinação de açúcares solúveis e redutores foram obtidos tendo-se colocado $40 \mathrm{mg}$ de folhas desidratadas e maceradas em solução etanólica a $80 \%$; o amido em solução de ácido perclórico a $30 \%$. As análises dos teores de amido e de açúcares solúveis foram realizadas pelo método antrona, e a análise dos teores de açúcares redutores, pelo método DNS (ácido dinitrosalicílico).

Em junho de 2010 e junho de 2011, período de colheita, foram avaliados o número de frutos e a produção $(\mathrm{kg})$ por planta.

Os dados foram submetidos à análise de variância e à regressão polinomial em função do tempo, a $5 \%$ de significância. Os modelos foram escolhidos com base na significância dos coeficientes de regressão, tendo-se utilizado o teste $\mathrm{t}$, a $5 \%$ de probabilidade.

\section{Resultados e Discussão}

Observou-se interação entre as épocas de amostragem foliar e os anos de avaliação, em todas as variáveis avaliadas $(p<0,05)$. Na safra 2009/2010, os maiores teores de açúcares solúveis nas folhas $\left(34,4 \mathrm{mg} \mathrm{g}^{-1}\right)$ foram observados aos 35 dias após o início do pleno florescimento; já em 2010/2011, os teores máximos $\left(87,9 \mathrm{mg} \mathrm{g}^{-1}\right)$ foram obtidos aos 44 dias após o pleno florescimento. Após esses períodos de amostragem, os teores foliares de açúcares solúveis diminuíram, em ambos os anos (Figura 2). A diferença observada entre os teores foliares de açúcares nas duas safras deveuse, possivelmente, à alternância de produção, em que a alta demanda de plantas por reservas nutricionais em um ano é seguida da redução destas no ano seguinte, frequentemente com reflexos sobre a produção (Cruz et al., 2011)
A disponibilidade de açúcares na planta aumentou quando os frutilhos estavam com diâmetro de 5 a $10 \mathrm{~mm}$ (Figura 3), na fase de queda fisiológica, quando estes são drenos de consumo, em decorrência da elevada quantidade de energia utilizada durante o
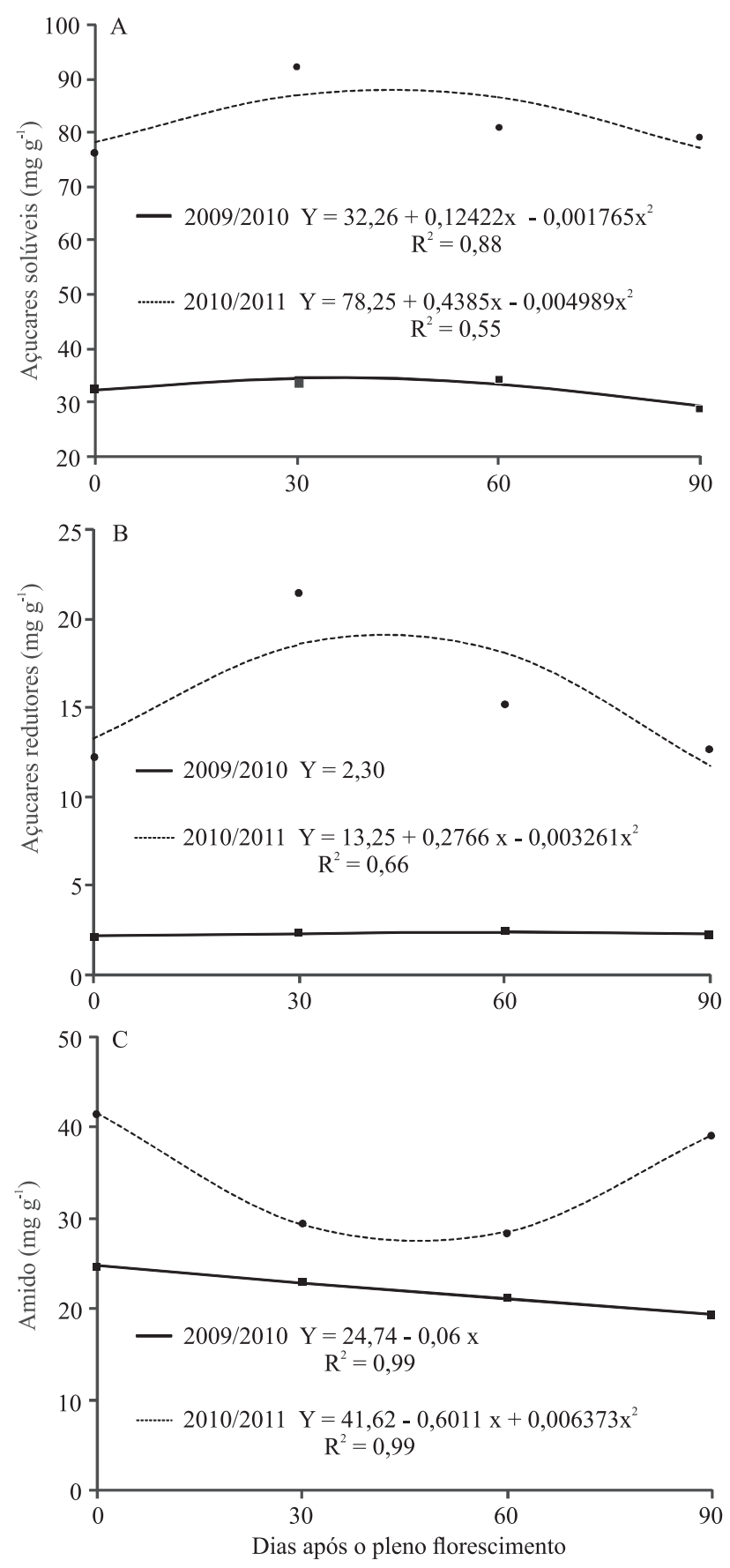

Figura 2. Efeito da época de amostragem sobre os teores foliares de: A, açúcares solúveis; B, açúcares redutores; e C, amido, em tangerineira 'Ponkan' (Citrus reticulata), nas safras de 2009/2010 e 2010/2011. 
período de divisão celular, na fase I de crescimento (Mehouachi et al., 1995).

Ruiz et al. (2001) relataram incremento dos teores foliares de carboidratos solúveis até os 36 dias, em laranjeira 'Washington Navel' [C. sinensis (L.) Osbeck], com posterior redução até os 90 dias. $\mathrm{O}$ aumento na disponibilidade de carboidratos solúveis na fase de queda fisiológica está associado ao aumento da fixação de frutilhos pela planta cítrica (Prado et al., 2007).

A queda nos teores foliares de carboidratos, durante $o$ período final de abscisão dos frutilhos, pode ser atribuída à utilização destes pelas plantas, para a manutenção e o crescimento dos frutos fixados (Figura 2), uma vez que, em razão da alta demanda por fotoassimilados pelos frutilhos, a planta torna essas reservas disponíveis para os drenos. O consumo de carboidratos no período final de abscisão dos frutos também foi verificado por Prado et al. (2007), em laranjeira 'Valência'.

Quanto aos teores foliares de açúcares redutores (glicose e frutose), os maiores valores foram observados no segundo ano de avaliação (2010/2011), em todas as épocas de amostragem (Figura 2). Em 2009/2010, os conteúdos de açúcares redutores nas plantas não variaram em função das épocas, com valores em torno de 2,3 $\mathrm{mg} \mathrm{g}^{-1}$, na matéria seca, semelhantes aos encontrados por Ruiz et al. (2001) e por Monerri et al. (2011), em laranjeiras. Essa constância nos teores de açúcares redutores nas folhas, durante o período de avaliação, provavelmente se deveu à alta conversão de reservas em açúcares solúveis, o que resultou em

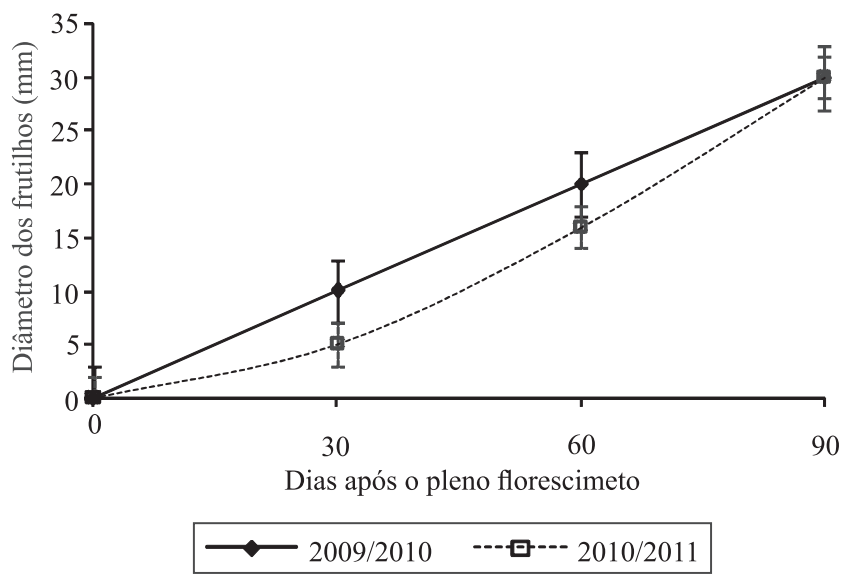

Figura 3. Diâmetro transversal dos frutilhos $(\mathrm{mm})$ de tangerineira 'Ponkan' (Citrus reticulata) em função das épocas de amostragem foliar, nas safras de 2009/2010 e 2010/2011. As barras indicam o desvio-padrão. menor conversão de sacarose em glicose e frutose (açúcares redutores).

No segundo ano (2010/2011), o teor foliar dos açúcares redutores apresentou comportamento quadrático, com maior valor $\left(19,1 \mathrm{mg} \mathrm{g}^{-1}\right)$ aos 42 dias após o pleno florescimento.

Os teores foliares de amido diminuíram de forma linear, no primeiro ano de avaliação (2009/2010), com $24,7 \mathrm{mg} \mathrm{g}^{-1}$ na fase de pleno florescimento e $19,3 \mathrm{mg} \mathrm{g}^{-1}$ aos 90 dias após o pleno florescimento (Figura 2). No segundo ano (2010/2011), os maiores teores $\left(41,6 \mathrm{mg} \mathrm{g}^{-1}\right)$ foram constatados no pleno florescimento, tendo diminuído para $27,4 \mathrm{mg} \mathrm{g}^{-1}$ aos 47 dias. Após esse dia, os teores voltaram a aumentar, até os 90 dias após o pleno florescimento, quando atingiram $39,1 \mathrm{mg} \mathrm{g}^{-1}$ de amido nas folhas.

A redução nos teores foliares de amido após o florescimento ocorre porque a demanda por fotoassimilidos aumenta nos drenos, e os carboidratos de reservas (amido) são convertidos em açúcares solúveis, disponíveis para uso no estabelecimento e na fixação dos frutos (Prado et al., 2007).

De acordo com Cruz et al. (2007), há intenso consumo de carboidratos no início do florescimento, para a formação das brotações vegetativas e floríferas, o que resulta na redução dos teores foliares de amido (Figura 2). Após a abscisão natural de frutilhos, a competição dos drenos por carboidratos diminui, o que pode favorecer a elevação dos teores de amido nas folhas, pelo transporte das raízes (Mahouachi et al., 2009) ou pelo aumento nas taxas fotossintéticas no início do verão (Pereira et al., 2011; Ribeiro et al., 2012).

Quando o diâmetro transversal dos frutilhos estava entre 12 e $18 \mathrm{~mm}$ (Figura 3), no período entre 35 e 50 dias após o pleno florescimento, os teores foliares dos carboidratos solúveis e redutores estavam mais elevados, e os de amido, mais baixos (Figura 2). Nessa época, foi observada a maior demanda por fotoassimilados pelos frutilhos, pois o amido presente nas folhas foi convertido em açúcares disponíveis, utilizados pelos drenos. Esse comportamento comprova a hipótese de que o raleio pode ser ineficiente quando realizado com os frutilhos no estádio de crescimento avançado, uma vez que, neste caso, o gasto de fotoassimilados já pode ter sido grande (Ruiz et al., 2001).

Portanto, a melhor época para a realização do raleio parece ser logo após a fase de queda fisiológica, quando os frutilhos atingem cerca de $18 \mathrm{~mm}$, a partir 
dos 50 dias após o pleno florescimento (Figura 3). Nesse ponto, ocorre aumento significativo nos teores de açúcares solúveis em decorrência da mobilização do amido (Figura 2). Antes desse período, o raleio pode ser não satisfatório porque a eliminação de algumas flores, ainda presentes nas plantas, favoreceria a fixação de frutilhos, o que poderia neutralizar o efeito do raleio químico (Zaragoza et al., 1992).

Os menores teores foliares de carboidratos no primeiro ano (2009/2010) podem estar relacionados à menor produção de frutos, que nessa safra foi de 220 frutos $(38,50 \mathrm{~kg})$ por tangerineira. No segundo ano, foram obtidas 465 tangerinas $(63,25 \mathrm{~kg})$ por planta. Essa relação evidencia a importância dos carboidratos na formação e na fixação das flores, e, portanto, no estabelecimento da produção de frutos (Cruz et al., 2007; Prado et al., 2007; Monerri et al., 2011).

De forma complementar, fica evidente a participação dos carboidratos foliares na alternância de produção das tangerineiras 'Ponkan'. Assim, de acordo com os resultados de duas safras, o menor conteúdo de carboidrato foliar resultou em menor número de fruto por planta, no primeiro ano, o que provavelmente contribuiu para o acúmulo de carboidratos nas folhas e a maior produção no ano seguinte, o que evidencia um processo autorregulado. Nebauer et al. (2011) constataram comportamento semelhante em laranjeira 'Salustiana', e Moreira et al. (2013a, 2013b), em tangerineira 'Ponkan'.

\section{Conclusões}

1. Os teores foliares de carboidratos solúveis aumentam e os de amido diminuem entre os 35 e 50 dias após o pleno florescimento.

2. No final da fase de fixação dos frutilhos, a partir dos 50 dias após o pleno florescimento, os teores de açúcares solúveis nas folhas diminuem.

3. A melhor época para a realização do raleio químico em tangerineira 'Ponkan' é logo após a fase de queda fisiológica, quando os frutilhos atingirem em torno de $18 \mathrm{~mm}$, em torno dos 50 dias após o pleno florescimento.

\section{Agradecimentos}

Ao Conselho Nacional de Desenvolvimento Científico e Tecnológico $(\mathrm{CNPq})$ e à Coordenação de Aperfeiçoamento de Pessoal de Nível Superior (Capes), pela concessão de bolsas de estudo.

\section{Referências}

BOLDINGH, H.; SMITH, G.S.; KLAGES, K. Seasonal concentrations of non-structural carbohydrates of five Actinidia species in fruit, leaf and fine root tissue. Annals of Botany, v.85, p.469-476, 2003. DOI: 10.1006/anbo.1999.1094.

BUSTAN, A.; GOLDSCHMIDT, E.E. Estimating the cost of flowering in a grapefruit tree. Plant Cell and Environment, v.21, p.217-224, 1998. DOI: 10.1046/j.1365-3040.1998.00267.x.

CRUZ, M. do C.M. da; MOREIRA, R.A. Production regularity of 'Ponkan' mandarin trees submitted to chemical thinning. Semina: Ciências Agrárias, v.33, p.2163-2172, 2012. DOI: 10.5433/1679-0359.2012v33n6p2163.

CRUZ, M. do C.M. da; RAMOS, J.D.; LIMA, L.C. de O.; MOREIRA, R.A.; RAMOS, P. de S. Qualidade de frutas de tangerineira 'Ponkan' submetidas ao raleio químico. Revista Brasileira de Fruticultura, v.31, p.127-134, 2009. DOI: 10.1590/S0100-29452009000100019.

CRUZ, M. do C.M. da; RAMOS, J.D.; MOREIRA, R.A.; MARQUES, V.B. Raleio químico na produção de tangerina 'Ponkan'. Revista Brasileira de Fruticultura, v.33, p.279-285, 2011. DOI: 10.1590/S0100-29452011005000040.

CRUZ, M. do C.M. da; RAMOS, J.D.; MOREIRA, R.A.; SANTOS, V.A. dos. Crescimento de tangerinas 'Ponkan' em plantas submetidas ao raleio químico. Revista Ceres, v.57, p.500-505, 2010.

CRUZ, M. do C.M. da; SIQUEIRA, D.L. de; SALOMÃO, L.C.C.; CECON, P.R.; SANTOS, D. dos. Teores de carboidratos em limeiras ácidas 'Tahiti' tratadas com paclobutrazol. Revista Brasileira de Fruticultura, v.29, p.222-226, 2007. DOI: 10.1590/ S0100-29452007000200007.

DUARTE, T.F.; BRON, I.U.; RIBEIRO, R.V.; MACHADO, E.C.; MAZZAFERA, P.; SHIMIZU, M.M. Efeito da carga pendente na qualidade de frutos de laranjeira 'Valência'. Revista Brasileira de Fruticultura, v.33, p.823-829, 2011. DOI: 10.1590/ S0100-29452011005000098.

MAIA, E.; SIQUEIRA, D.L. de; CECON, P.R. Produção, florescimento e frutificação de tangerineira 'Poncã' submetida à aplicação de ácido giberélico. Ciência Rural, v.40, p.507-512, 2010. DOI: $10.1590 / \mathrm{S} 0103-84782010005000025$.

MAHOUACHI, J.; IGLESIAS, D.J.; AGUSTÍ, M.; TALÓN, M. Delay of early fruitlet abscission by branch girdling in citrus coincides with previous increases in carbohydrate and gibberellin concentrations. Plant Growth Regulation, v.58, p.15-23, 2009. DOI: $10.1007 / \mathrm{s} 10725-008-9348-6$.

MEHOUACHI, J.; SERNA, D.; ZARAGOZA, S.; AGUSTI, M.; TALON, M.; PRIMO-MILLO, E. Defoliation increases fruit abscission and reduces carbohydrate leaves in developing fruits and woody tissues of Citrus unshiu. Plant Science, v.107 p.189-197, 1995. DOI: 10.1016/0168-9452(95)04111-7.

MONERRI, C.; FORTUNATO-ALMEIDA, A.; MOLINA, R.V.; NEBAUER, S.G.; GARCÍA-LUIS, A.; GUARDIOLA, J.L. Relation

Pesq. agropec. bras., Brasília, v.49, n.1, p.34-39, jan. 2014

DOI: 10.1590/S0100-204X2014000100005 
of carbohydrate reserves with the forthcoming crop, flower formation and photosynthetic rate, in the alternate bearing 'Salustiana' sweet orange (Citrus sinensis L.). Scientia Horticulturae, v.129, p.71-78, 2011. DOI: 10.1016/j.scienta.2011.03.009.

MOREIRA, R.A.; MOREIRA, R.C.A.; RAMOS, J.D.; SILVA, F.O. dos R. Regularidade da produção de tangerineiras 'Ponkan' submetidas ao raleio químico bianual. Revista Brasileira de Fruticultura, v.33, p.235-240, 2011b. DOI: 10.1590/ S0100-29452011000500028.

MOREIRA, R.A.; RAMOS, J.D.; CRUZ, M. do C.M. da; PANTOJA, L. de; SANTOS, A.S. dos. Carbohydrate levels in the leaves and production consistency of the Ponkan tangerine when thinned out with Ethephon. Revista Ciência Agronômica, v.44, p.571-577, 2013a. DOI: 10.1590/ S1806-66902013000300020.

MOREIRA, R.A.; RAMOS, J.D.; CRUZ, M. do C.M. da; PANTOJA, L. de; SANTOS, A.S. dos. Leaf carbohydrates in 'Ponkan' mandarin fruit quality under chemical thinning. Acta Scientiarum. Agronomy, v.35, p.349-356, 2013b. DOI: 10.4025/ actasciagron.v35i3.16219.

MOREIRA, R.A.; RAMOS, J.D.; CRUZ, M. do C.M. da; ARAÚJO, N.A. de; MARQUES, V.B. Production of 'Ponkan' mandarin trees submitted to chemical thinning. Revista Brasileira de Ciências Agrárias, v.6, p.287-291, 2011a. DOI: 10.5039/agraria.v6i2a1190.

MOREIRA, R.A.; RAMOS, J.D.; SILVA, F.O. dos R.; COSTA, A.C. Qualidade de tangerinas 'Ponkan' em função da regularidade do raleio químico. Pesquisa Agropecuária Tropical, v.42, p.303-309, 2012. DOI: 10.1590/S1983-40632012000300009.

NEBAUER, S.G.; RENAU-MORATA, B.; GUARDIOLA, J.L.; MOLINA, R.V. Photosynthesis down-regulation precedes carbohydrate accumulation under sink limitation in Citrus. Tree Physiology, v.31, p.169-177, 2011. DOI: 10.1093/treephys/tpq103.

PEREIRA, C.S.; SIQUEIRA, D.L. de; SALOMÃO, L.C.C.; CECON, P.R.; SANTOS, D. dos. Teores de carboidratos nas folhas e produção de limeiras ácida 'Tahiti' aneladas e tratadas com ácido giberélico. Revista Brasileira de Fruticultura, v.33, p.706-712, 2011. DOI: 10.1590/S0100-29452011005000089.

PRADO, A.K. de S.; MACHADO, E.C.; MEDINA, C.L.; MACHADO, D.F.S.P.; MAZZAFERA, P. Florescimento e frutificação em laranjeiras 'Valência' com diferentes cargas de frutos e submetidas ou não à irrigação. Bragantia, v.66, p.173-182, 2007. DOI: 10.1590/S0006-87052007000200001.

RAMOS, J.D.; CRUZ, M. do C.M. da; PASQUAL, M.; HAFLE, O.M.; RAMOS, P. de S.; ROSSI, E.P. Ethephon no raleio de tangerinas 'Ponkan'. Ciência Rural, v.39, p.236-240, 2009. DOI: 10.1590/S0103-84782009000100038.

RIBEIRO, R.V.; MACHADO, E.C.; ESPINOZA-NÚÑEZ, E.; RAMOS, R.A.; MACHADO, D.F.S.P. Moderate warm temperature improves shoot growth, affects carbohydrate status and stimulates photosynthesis of sweet orange plants. Brazilian Journal of Plant Physiology, v.24, p.37-46, 2012. DOI: 10.1590/ S1677-04202012000100006.

RUIZ, R.; GARCIA-LUIS, A.; MONERRI, C.; GUARDIOLA, J.L. Carbohydrate availability in relation to fruitlet abscission in Citrus. Annals of Botany, v.87, p.805-812, 2001. DOI: 10.1006/ anbo.2001.1415.

ZARAGOZA, S.; TRENOR, I.; ALONSO, E.; PRIMO-MILLO, E.; AGUSTÍ, M. Treatments to increase the final fruit size on Satsuma 'Clausellina'. In: INTERNATIONAL CITRUS CONGRESS, 7. 1992, Acireale. Proceedings... Acireale: International Society of Citriculture, 1992. v.2, p.725-728.

Recebido em 20 de novembro de 2013 e aprovado em 20 de dezembro de 2013

Pesq. agropec. bras., Brasília, 49, n.1, p.34-39, jan. 2014 DOI: $10.1590 / \mathrm{S} 0100-204 X 2014000100005$ 